University of Montana

ScholarWorks at University of Montana

Public and Community Health Sciences Faculty

Publications

Public and Community Health Sciences

$11-2010$

\title{
Motivational Interviewing for Smoking Cessation in College Students: A Group Randomized Controlled Trial
}

\author{
Kari J. Harris \\ University of Montana - Missoula, kari.harris@umontana.edu \\ Delwyn Catley \\ University of Missouri - Kansas City \\ Glenn E. Good \\ University of Missouri \\ Nikole J. Cronk \\ University of Montana - Missoula \\ Solomon W. Harrar \\ University of Montana - Missoula \\ See next page for additional authors \\ Follow this and additional works at: https://scholarworks.umt.edu/pchs_pubs \\ Part of the Public Health Commons \\ Let us know how access to this document benefits you.
}

\section{Recommended Citation}

Harris, Kari J.; Catley, Delwyn; Good, Glenn E.; Cronk, Nikole J.; Harrar, Solomon W.; and Williams, Karen B., "Motivational Interviewing for Smoking Cessation in College Students: A Group Randomized Controlled Trial" (2010). Public and Community Health Sciences Faculty Publications. 35.

https://scholarworks.umt.edu/pchs_pubs/35

This Article is brought to you for free and open access by the Public and Community Health Sciences at ScholarWorks at University of Montana. It has been accepted for inclusion in Public and Community Health Sciences Faculty Publications by an authorized administrator of ScholarWorks at University of Montana. For more information, please contact scholarworks@mso.umt.edu. 


\section{Authors}

Kari J. Harris, Delwyn Catley, Glenn E. Good, Nikole J. Cronk, Solomon W. Harrar, and Karen B. Williams 
Published in final edited form as:

Prev Med. 2010 November ; 51(5): 387-393. doi:10.1016/j.ypmed.2010.08.018.

\title{
Motivational interviewing for smoking cessation in college students: A group randomized controlled trial
}

\author{
Kari Jo Harris, Ph.D., M.P.H. ${ }^{1}$, Delwyn Catley, Ph.D. ${ }^{2}$, Glenn E. Good, Ph.D. ${ }^{3}$, Nikole J. Cronk, \\ Ph.D. ${ }^{3}$, Solomon Harrar, Ph.D. ${ }^{1}$, and Karen B. Williams, Ph.D. ${ }^{4}$ \\ ${ }^{1}$ The University of Montana \\ ${ }^{2}$ University of Missouri - Kansas City \\ 3University of Missouri -- Columbia \\ ${ }^{4}$ University of Missouri - Kansas City School of Medicine
}

\section{Abstract}

Objective-To examine the efficacy of four individually-delivered Motivational Interviewing counseling sessions for smoking cessation versus a matched intensity comparison condition.

Method-From 2006-2009, students attending college in the Midwest smoking at least 1 of 30 days were recruited regardless of their interest in quitting. 30 fraternities and sororities were randomized, resulting in 452 participants.

Results-No significant differences were found for 30-day cessation between treatment and comparison at end of treatment $(31.4 \%$ vs $28 \%$, OR $=1.20,95 \%$ CI $.72,1.99)$ or at follow-up $(20.4 \%$ vs $24.6 \%$, OR=.78, 95\% CI .50,1.22). Predictors of cessation at follow-up, regardless of condition, included more sessions attended (OR 1.2, 95\% CI 1.1,1.8) and more cigarettes smoked in 30 days at baseline (OR 4.7, 95\% CI 2.5,8.9). The odds of making at least one quit attempt were significantly greater for those in the smoking group at end of treatment (OR 1.75, 95\% CI 1.11,2.74) and followup (OR 1.66, 95\% CI 1.11,2.47). Modeling showed reduction in days smoked for both groups. At end of treatment, more frequent smokers in the treatment condition had greater reductions in days smoked.

Conclusion-Motivational Interviewing for smoking cessation is effective for increasing cessation attempts and reducing days smoked in the short run.

\section{Introduction}

Addressing smoking in the nearly 17 million young adults enrolled in colleges and universities in the United States (U.S. Census Bureau, 2009) is a national health priority. Cigarette smoking

(C) 2010 Elsevier Inc. All rights reserved.

Correspondence concerning this article should be addressed to Kari Jo Harris, Ph.D., M.P.H., School of Public and Community Health Sciences, 352 Skaggs Building, The University of Montana, Missoula, MT 59818; phone (406) 243-4685; fax 888-849-9597;

kari.harris@umontana.edu. 
among college students is of particular concern because their smoking prevalence has not decreased as it has among the general population (Johnston et al., 2007; Rigotti et al., 2000; Thompson et al., 2007). Studies characterize college as a time of smoking transitions, including smoking initiation (Wetter et al., 2004). Although nearly all students report that their smoking is temporary (Kenford et al., 2005) and most do not smoke every day (Fiore et al., 1993; Wetter et al., 2004), longitudinal studies have shown that $50 \%$ who smoke occasionally and $87 \%$ who smoke daily continue smoking throughout college (Wetter et al., 2004) and many continue after college (Everett et al., 1999).

Characteristics of college smokers that make it difficult to address smoking, especially early in their smoking career, include not considering themselves to be smokers (Berg et al., 2009; Moran et al., 2004; Waters et al., 2006), low motivation to stop (Waters et al., 2006), and infrequent use of cessation aids (Curry et al., 2007; Fiore et al., 1990). There are a growing number of college initiatives to address smoking (Harris et al., 2009b), yet few cessation interventions have been evaluated (Bader et al., 2007; Murphy-Hoefer et al., 2005) and none have been disseminated widely. Prior studies of smoking interventions designed for college students show mixed results (e.g., (Thompson et al., 2010)) and, when positive, lack evaluation of sustained effects (An et al., 2008), show marginal effects (Prokhorov et al., 2008), or lack random assignment (Travis and Lawrance, 2009).

In the present study we examined the efficacy of a Motivational Interviewing (MI)-based treatment (Miller, 1996; Miller and Rollnick, 1991) for motivating college students to quit smoking. MI is designed to enhance motivation for behavior change by guiding clients to explore and resolve their ambivalence in the direction of change. It combines a "clientcentered" stance, in which clinicians work from their clients' perspectives, with specific methods to increase clients' consideration of the advantages of change. Direct persuasion is avoided and clinicians emphasize clients' autonomy regarding whether or not to make changes. MI has demonstrated efficacy for addressing addictive behaviors and other health behaviors (Hettema et al., 2005; Rubak et al., 2005). With respect to smoking, MI has been found to increase smokers' readiness to quit (Butler et al., 1999), increase quit attempts (Borrelli et al., 2005; Wakefield et al., 2004), reduce smoking level (Borrelli et al., 2005), and in some studies to enhance cessation (Curry, 2003; Fiore et al., 2008; Pbert et al., 2006; Soria et al., 2006; Valanis et al., 2001) including among adolescents (Borrelli et al., 2005; Butler et al., 1999; Colby et al., 2005; Curry, 2003; Pbert et al., 2006; Soria et al., 2006; Valanis et al., 2001; Wakefield et al., 2004). One study of students enrolled in community colleges who smoked more than 10 cigarettes per day showed marginal effects for cessation at 10 months using an MI-based approach combined with personalized computer feedback on respiratory health (Prokhorov et al., 2008). Counselor fidelity to MI principles was not monitored and students in the control group received brief advice to quit, which was not matched in time or intensity to the treatment group.

The purpose of the current study was to examine the efficacy of four individually-delivered MI counseling sessions for smoking cessation, reduction, and quit attempts among undergraduate university students. Using proactive recruitment methods (Harris et al., 2003), this study enrolled both infrequent and daily smokers, regardless of their interest in quitting. The study included on-going monitoring of intervention fidelity and compared the intervention to a similar MI-based intervention matched in duration, but focused on motivating students to increase their fruit and vegetable consumption. 


\section{Methods}

\section{Recruitment and randomization}

Students in 13 sororities and 17 fraternities were screened at chapter meetings at the start of three successive fall semesters (2006-2008) at one large Midwestern university. The organized social system provided an opportunity to maximize recruitment of smokers who were not necessarily interested in addressing their tobacco use, but were supportive of their chaptersponsored health program (Davidson et al., 2010; Varvel et al., 2008). At screening, eligible students reported smoking cigarettes one or more of the past 30 days, had not used medications to help quit smoking in the past 30 days, were at least 18 years old, expected to be enrolled in college for the academic year, and were interested in participating in a health study. Eligible students were invited to enroll by completing a computerized baseline survey within a week of screening. In an attempt to maintain homogeneity of cluster size, up to 30 randomly selected eligible members per chapter were invited to baseline.

For each cohort, after all students completed the baseline survey, fraternities and sororities were randomized to either treatment (smoking) or comparison (fruits/vegetables) conditions without blocking. Randomization occurred at the chapter level to minimize potential contamination across conditions. Neither participants nor study staff could be masked to group assignment. Study procedures were reviewed and monitored by Institutional Review Boards at the University of Montana and University of Missouri.

\section{Conditions}

Participants in both conditions received up to four one-on-one sessions of MI with a trained counselor. The first three sessions occurred approximately every other week following baseline assessment and the fourth session occurred approximately 4 weeks after session 3 to allow for a 30-day reporting period at the last session. Sessions were typically 20-30 minutes and were audiotaped for supervision. In the treatment condition, participants received MI focused on motivating and assisting participants to quit cigarette smoking while in the comparison condition participants received MI focused on increasing consumption of fruits and vegetables to at least 5 servings a day. Interventions were matched in therapeutic approach and duration. Self-help guides tailored for college students that discussed the benefits and methods of quitting/eating fruits and vegetables were developed and provided to all participants at their first session. Both interventions implemented MI using a flexible session outline that included an exploration of the pros and cons of quitting/eating 5 a day, an exploration of motivation and confidence to quit/eat 5 a day, and a consideration of the relation between participants' most important values and quitting/eating 5 a day. In sessions $2-4$, counselors could invite participants to choose from a menu of discussion topics. In the treatment condition, example topics included: cigarettes as a nicotine delivery device, addiction, and the health effects of smoking. Participants in the smoking condition who reported respiratory symptoms at the beginning of each session were also offered the opportunity to discuss the results of their respiratory symptom report. A MI style was used to provide feedback on the presence of respiratory symptoms as an early indicator of negative health effects. For students who became motivated to change during the sessions, counselors used a MI style to follow the outline of a "plan module" in which cognitive-behavioral principles were used (e.g., goal-setting, management of internal and external cues, self-rewards) to develop a change plan, which is consistent with Phase II of MI (Miller and Rollnick, 2002). Students who smoked at a sufficiently high level were encouraged to use pharmacotherapy that was obtainable through university and other resources. 


\section{Counselor training and fidelity}

Counselors were 23 graduate-level clinical or counseling psychology students who received more than 100 hours of training in smoking, fruit/vegetable intake and the conduct of MI from experts in each of these topics. The MI training was in accord with guidelines and training materials produced by the Motivational Interviewing Network of Trainers (Miller and Rollnick, 1999). Counselors worked across conditions and were trained to consider increased fruit/ vegetable intake and smoking cessation as equally important study outcomes. We assessed fidelity to MI using supervisors' rating of counselors' in-session proficiency on 18 items (Catley, 2003), including reflective listening, asking permission, and MI spirit, used in prior studies (Ahluwalia et al., 2002; Ahluwalia et al., 2006; Okuyemi et al., 2007). All counselors demonstrated proficiency, 4 or higher on a 1 (poor) to 7 (excellent) point rating, during training as a hiring prerequisite and throughout the study. To maintain fidelity throughout the study counselors participated in weekly group supervision with doctoral-level supervisors who reviewed one randomly chosen or particularly challenging audiotaped session per counselor. Counselors whose fidelity scores dropped below proficiency received additional supervision and remediation until scores increased or the counselor was dismissed. Fidelity scores remained high throughout, with a mean rating of $6.12(.87 \mathrm{SD})$ on the MI-spirit item.

\section{Measures}

Participants completed computer-administered assessments at baseline, at each of the four counseling sessions, and six months after randomization. Past 30-day smoking days and number of cigarettes smoked was assessed using the Timeline Follow-Back Method (Harris et al., 2009a; Sobell and Sobell, 1992) at all time points. Saliva samples from those who reported cessation at six months were assessed for cotinine (Benowitz, 2002; Jacob et al., 1981; Spierto et al., 1988). Other measures included single items to assess making a serious quit attempt for at least 24 hours (Ahluwalia et al., 2002; Centers for Disease Control and Prevention, 2007; Richter et al., 2001), motivation and confidence to quit (0-10 scale, $10=$ very motivated/ confident) (Boardman et al., 2005), number of five best friends who smoke (US Department of Commerce and Census Bureau, 2004), romantic partners' smoking status (created for this study), self-identification as a smoker (Waters et al., 2006), days consuming at least one drink of alcohol (Centers for Disease Control and Prevention, 1997), servings of fruits and vegetables eaten per day (Resnicow et al., 2003), and dependence using the 10-item Hooked on Nicotine Checklist (Wellman et al., 2004; Wellman et al., 2005).

\section{Statistical analysis}

The primary outcome was 30-day point-prevalence abstinence from cigarettes 6 months following randomization based on self-report and corrected by biochemical verification. Secondary outcomes included 30-day point prevalence at end of treatment, making any quit attempt since baseline at the end of treatment and 6 months, and reduction in smoking days at the end of treatment and 6 months. As chapter was the unit of randomization, we anticipated the possibility of lack of independence in the outcomes and used multilevel analyses. Intracluster correlation coefficients (ICC's) were computed using an unconditional means model on outcomes with chapter as the random effect. Preliminary bivariate analyses were also conducted to determine if treatment groups systematically differed on any baseline factors that serve as potential moderators in the primary analyses.

Cessation outcomes analyses were conducted using an intention-to-treat approach with nonrespondents classified as continuing smokers. Multilevel logistic regression modeling was used to compare the rates of 30-day cessation between groups separately for end of treatment and 6-month follow-up. Since groups were significantly unequal at baseline with respect to gender, modeling was conducted with and without adjusting for gender. Multilevel logistic regression was used to separately model quit attempts at the two time points as a function of group 
assignment. To compare the change in number of days smoked from baseline between groups at each time point, a Poisson Regression Model was initially fitted using condition as the predictor variable and baseline number of days smoked as a covariate. Since we included those who quit in the analysis to profile the entire sample, there were more zero days smoked than could be adequately modeled and cluster correlation needed to be accounted for. To address these two issues, we fitted a Zero-Inflated Poisson Mixed Model using chapter as a random effect (Hall, 2000). Statistical analyses were completed using SAS statistical software version 9.1 (SAS Institute Inc.), with an alpha of .05 used for determining statistical significance.

\section{Results}

\section{Preliminary Analyses}

ICCs for cessation (intention-to-treat) at end of treatment and follow-up, quit attempt at end of treatment, quit attempts at follow-up and days smoking at follow-up were $.032, .003, .023$, . 017 and .059 , respectively. ICC's represent the amount of variance for each outcome explained by chapter clusters. Additionally, effect of cohort across the 3-year study was analyzed to determine if it could be collapsed across cohorts. Multilevel logistic regression determined that neither year nor year by condition interaction clustered within chapter were significantly related to cessation ( $\mathrm{p}=0.92$ and 0.37 , respectively), and therefore were omitted from subsequent analyses. Biochemical verification procedures at 6 months resulted in one participant (who was in the smoking condition) being re-coded as continuing to smoke (i.e., cotinine values were higher than the $15 \mathrm{ng} / \mathrm{ml}$ expected for non-smokers and there was no report of other tobacco use).

\section{Study Participation}

The study flow (Figure 1) began with agreement by the 30 largest chapters of the 41 with residential programs to participate. Chapters ranged from 58 to 247 members, with an average of $76 \%$ of members participating in screening. Of 3,276 students screened, 761 met eligibility criteria, 452 completed baseline assessments (59\% enrollment rate). Fifteen chapters were randomly assigned to each condition, with allocations of 245 participants in the treatment condition and 207 participants in the comparison condition. The mean (SD) number of participants per chapter was 15.07 (5.59). Forty-eight participants withdrew reporting insufficient time or interest. Overall, 73\% (329/452) completed three or more sessions. Participation did not differ between conditions nor was retention predicted by participants' characteristics such as gender, year in school, baseline smoking, or motivation to quit (Davidson et al., 2010).

\section{Baseline Characteristics}

Groups were similar across demographic and smoking characteristics except that more females were allocated by chance to the comparison condition (Table 1). Most participants were white, lived in the chapter house, ate fewer than 5 fruits/vegetables per day, and drank alcohol frequently. Most did not smoke every day and, on average, smoked about 8 out of the past 30 days and 3-4 cigarettes on days they smoked. Participants generally reported moderate motivation and high confidence in their ability to quit smoking.

\section{Smoking Cessation}

Self-reported quit rates (30-day point prevalence) with missing data coded as smokers and adjusted for cotinine results at 6 months are presented in Table 2. No significant differences between groups were found at either timepoint. This result was not altered by adjusting for the gender inequity across groups and gender was therefore eliminated from subsequent analyses. Across both conditions, intention-to-treat quit rates were 25\% (115/452) at end of treatment 
and 22\% (101/452) at 6 months. Similar results were obtained for self reported quit rates among only those who completed assessments, with quit rates of $38.9 \%(72 / 185)$ and $32.2 \%(47 / 146)$ at end of treatment $(\mathrm{p}=0.21)$ and $26.2 \%(51 / 195)$ and $31.9 \%(51 / 160)$ at 6 months $(\mathrm{p}=0.22)$, for the treatment and comparison conditions, respectively.

We examined potential moderators of the intervention effects on cessation using a series of logistic regression models including interaction terms for condition and baseline characteristic (e.g., motivation to quit, confidence to quit, total number of cigarettes smoked in 30 days, nicotine addiction, and number of sessions attended). More sessions attended (OR 1.2, 95\% CI 1.1,1.8) and number of cigarettes smoked in 30 days (OR 4.7, 95\% CI 2.5,8.9) were significantly related to quitting at 6 months. However, the interaction terms between these variables and condition were not significant (both $\mathrm{ps}=0.74$ ) suggesting that treatment effects did not differ in relation to sessions attended or number of cigarettes smoked.

\section{Quit Attempts}

Participants were dichotomized according to whether they reported making any serious attempt to quit versus no attempt by end of treatment or by 6 months. Table 3 shows results of the multilevel logistic regression (clustered by chapter) modeling any quit attempt. The odds of making a quit attempt were significantly greater for the smoking group at end of treatment and follow-up.

\section{Smoking Reduction}

Results from the Zero-Inflated Poisson Mixed Model exploring the effects of the intervention on reducing number of days smoked are shown in Figure 2 for end of treatment (top panel) and follow-up (lower panel). Panels depict an overall reduction in smoking across both conditions, as both fitted curves are below the 45 degree dotted line that represents no change from baseline. Reduction in days smoked was accompanied by a corresponding reduction in total cigarettes smoked in a 30-day period (data not shown). At end of treatment, there is relative advantage for the treatment condition on reducing number of days smoked except among those smoking only a few days at baseline (as indicated by the smoking condition curve being below the fruit/vegetable condition curve except when days smoked at baseline is very low). At follow-up there is a relative advantage for the treatment condition on reducing number of days smoked only when days smoked at baseline is high (as indicated by the smoking condition curve being below the comparison condition curve only when days smoked at baseline is high). To quantify these findings, we calculated the predicted reduction in number of days smoked between the two arms at end of treatment and follow-up for 3 levels of baseline smoking (Table 4). At end of treatment, reductions were significantly greater (about 2 and 7 days greater) in the treatment group for those smoking 20 and 30 days at baseline. At follow-up, the predicted difference in reductions was about 2 days less for the treatment group when baseline smoking was 10 days. These results suggest the advantage of the smoking intervention on reduction is more pronounced as the number of days smoked at baseline increases.

\section{Discussion and Conclusions}

These findings for a MI-based intervention for smoking among a group of mostly non-daily smokers were mixed. Quit rates based on intention-to-treat analysis were relatively high across both conditions at end of treatment (25\%) and at six-month follow-up (22\%). Counter to the study hypothesis, no significant differences were found for cessation between treatment and comparison at the end of treatment or follow-up, which is consistent with some prior studies of MI for smoking cessation (Lundahl et al., 2010). Findings showing more quit attempts (throughout the study) and smoking reduction (at end of treatment only) in the treatment group 
suggest that the MI-smoking intervention had benefits that were not completely maintained over time.

Cessation rates in the current study are lower than the $41 \%$ cessation reported for a multicomponent internet-based intervention at the end of 30 weeks of treatment but higher than the $16 \%$ quit rate reported at 8 weeks (An et al., 2008). In that study, participants were paid to attend to intervention components and treatment was sustained for 30 weeks. Cessation rates steadily increased over time. Our quit rates may differ because of the greater intensity, but shorter duration of our intervention. It is also possible that including non-tobacco related content, such as general news and health stories embedded within the online college life magazine (An et al., 2008), that is non-threatening is potentially more effective for promoting cessation among infrequent smokers.

Predictors of cessation at follow-up included greater number of sessions attended, however there was no differential impact based on treatment assignment. This suggests that the comparison condition may have functioned as an active intervention for cessation. This is plausible since the content of the comparison group counseling sessions focused on reducing health and cancer risks by eating more fruits and vegetables. Prior studies have shown that smoking is correlated with a less-healthy diet (Balding and Macgregor, 1987; Dallongeville et al., 1998; McClure et al., 2009; McPhillips et al., 1994; Subar et al., 1990). Counselors in this study also reported that comparison group participants asked to discuss smoking, especially after successfully meeting their dietary goals. However, because we lacked a no treatment comparison group and observational studies suggest some spontaneous quitting over time is typical during college (Colder et al., 2006; Kenford et al., 2005; Wetter et al., 2004), it remains possible that the cessation intervention was ineffective. While an attention control provides a stronger comparison than a brief (or no treatment) control, non-health related content might be more suitable for these smokers.

Another predictor of cessation at follow-up was baseline number of cigarettes smoked in 30 days; however, contrary to the established literature, higher number of cigarettes predicted cessation, although there was no treatment interaction effect. Close examination with respect to level of smoking at end of treatment also suggests that there were generally greater reductions among those who smoked more at baseline. This effect appears to be stronger in the treatment group, particularly for heavy smokers. These findings together with the result of the An et al., 2008 study suggest that for infrequent smokers an "indirect" approach in which general health or another health topic is the focus may be more effective for smoking cessation. This is also consistent with counselor anecdotes that more infrequent smokers resisted the label "smoker" and the notion of "quitting." Conversely, regular smokers appear to have benefited more from the direct focus on smoking cessation rather than diet improvement. However, this effect appears subtle and is only apparent for one secondary outcome (smoking reduction). The different outcomes based on smoking level lend support to the importance of considering number of days smoked during intervention development for college students (Sutfin et al., 2009).

A number of limitations should be considered in interpreting the findings of this study. Because it is difficult to biochemically verify occasional smoking over a 30-day period, we used a "bogus pipeline" approach at follow-up. Participants were led to believe that their smoking status could be verified through saliva analysis. This appears to reduce inaccurate reporting (Murray and Perry, 1987), but it is possible that cessation rates were overestimated. While we performed exploratory analyses to investigate the potential for moderation, the study was not powered to detect interaction effects. It was not possible to isolate which element accounted for the observed treatment effects because MI was delivered using a flexible session outline and a menu of discussion topics including relevant respiratory symptoms. Another limitation 
is that participants were from a single Midwest campus characterized by generally healthy, white students with relatively high rates of drinking. Hence, results may not generalize to students with different demographic characteristics.

A unique feature of this study was the inclusion of a closely-matched attention comparison group that attempted to isolate the effects of MI targeting smoking cessation. However, in this case, the inclusion of a no treatment control would aid in the interpretation of the results obtained from the active interventions. A strength was the successful recruitment of 59\% of eligible smokers regardless of interest in quitting, suggesting the sample is likely representative of student smokers at a large Midwestern campus.

Overall these findings suggest that MI for smoking may have positive effects on quit attempts and number of days smoked, but that more effective and sustained interventions are needed. Together with prior research, these results also suggest that very infrequent smokers may benefit from interventions focusing on health without an explicit smoking focus.

\section{Acknowledgments}

The project described was supported by Award Number R01CA107191 from the National Cancer Institute. The content is solely the responsibility of the authors and does not necessarily represent the official views of the National Cancer Institute or the National Institutes of Health.

\section{References}

Ahluwalia JS, Harris KJ, Catley D, Okuyemi KS, Mayo MS. Sustained-release bupropion for smoking cessation in African Americans: a randomized controlled trial. JAMA 2002;288:468-474. [PubMed: 12132977]

Ahluwalia JS, Okuyemi K, Nollen N, Choi WS, Kaur H, Pulvers K, Mayo MS. The effects of nicotine gum and counseling among African American light smokers: a $2 \times 2$ factorial design. Addiction 2006;101:883-891. [PubMed: 16696632]

An LC, Klatt C, Perry CL, Lein EB, Hennrikus DJ, Pallonen UE, Bliss RL, Lando HA, Farley DM, Ahluwalia JS, Ehlinger EP. The RealU online cessation intervention for college smokers: a randomized controlled trial. Prev Med 2008;47:194-199. [PubMed: 18565577]

Bader P, Travis HE, Skinner HA. Knowledge synthesis of smoking cessation among employed and unemployed young adults. Am J Public Health 2007;97:1434-1443. [PubMed: 17600254]

Balding JW, Macgregor ID. Health-related behaviour and smoking in young adolescents. Public Health 1987;101:277-282. [PubMed: 3659241]

Benowitz NL. Biochemical verification of tobacco use and cessation. Nicotine Tob Res 2002;4:149-159. [PubMed: 12028847]

Berg CJ, Lust KA, Sanem JR, Kirch MA, Rudie M, Ehlinger E, Ahluwalia JS, An LC. Smoker selfidentification versus recent smoking among college students. Am J Prev Med 2009;36:333-336. [PubMed: 19201148]

Boardman T, Catley D, Mayo MS, Ahluwalia JS. Self-efficacy and motivation to quit during participation in a smoking cessation program. Int J Behav Med 2005;12:266-272. [PubMed: 16262545]

Borrelli B, Novak S, Hecht J, Emmons K, Papandonatos G, Abrams D. Home health care nurses as a new channel for smoking cessation treatment: outcomes from project CARES (Community-nurse Assisted Research and Education on Smoking). Prev Med 2005;41:815-821. [PubMed: 16182355]

Butler CC, Rollnick S, Cohen D, Bachmann M, Russell I, Stott N. Motivational consulting versus brief advice for smokers in general practice: A randomized trial. Br J Gen Pract 1999;49:611-616.

Catley, D. The KU “One Pass,” in Using Motivational Interviewing coding schemes. Greece: Motivational Interviewing Network of Trainers Forum, Crete; 2003.

Centers for Disease Control and Prevention. Youth Risk Behavior Surveillance: National College Health Risk Behavior Survey--United States, 1995. Morbidity \& Mortality Weekly Report. CDC Surveillance Summaries 1997;46:1-56. 
Centers for Disease Control and Prevention. Cigarette smoking among adults-United States, 2006. MMWR - Morbidity \& Mortality Weekly Report 2007;56:1157-1161. [PubMed: 17989644]

Colby SM, Monti PM, O'Leary Tevyaw T, Barnett NP, Spirito A, Rohsenow DJ, Riggs S, Lewander W. Brief motivational intervention for adolescent smokers in medical settings. Addict Behav 2005;30:865-874. [PubMed: 15893085]

Colder CR, Lloyd-Richardson EE, Flaherty BP, Hedeker D, Segawa E, Flay BR. The natural history of college smoking: trajectories of daily smoking during the freshman year. Addict Behav 2006;31:2212-2222. [PubMed: 16616816]

Curry SJ. Youth tobacco cessation: filling the gap between what we do and what we know. Am J Health Behav 2003;27 Suppl 2:S99-S102. [PubMed: 14521238]

Curry SJ, Sporer AK, Pugach O, Campbell RT, Emery S. Use of tobacco cessation treatments among young adult smokers: 2005 National Health Interview Survey. Am J Public Health 2007;97:14641469. [PubMed: 17600243]

Dallongeville J, Marecaux N, Fruchart JC, Amouyel P. Cigarette smoking is associated with unhealthy patterns of nutrient intake: a meta-analysis. J Nutr 1998;128:1450-1457. [PubMed: 9732304]

Davidson M, Cronk N, Harris KJ, Harrar S, Catley D, Good GE. Strategies to Recruit and Retain College Smokers in Cessation Trials. Research in Nursing \& Health 2010;33:144-155. [PubMed: 20196093]

Everett SA, Husten CG, Kann L, Warren CW, Sharp D, Crossett L. Smoking initiation and smoking patterns among US college students. Journal of American College Health 1999:55-60. [PubMed: 10500367]

Fiore, MC.; Jaen, CR.; Baker, TB., et al. Clinical Practice Guideline. . Department of Health and Human Services. Rockville, MD: Public Health Service; 2008. Treating Tobacco Use and Dependence: 2008 Update.

Fiore MC, Jorenby DE, Wetter DW, Kenford SL, Smith SS, Baker TB. Prevalence of daily and experimental smoking among University of Wisconsin-Madison undergraduates, 1989-1993. Wis Med J 1993;92:605-608. [PubMed: 8303895]

Fiore MC, Novotny TE, Pierce JP, Giovino GA, Hatziandreu EJ, Newcomb PA, Surawicz TS, Davis RM. Methods used to quit smoking in the United States. Do cessation programs help? JAMA 1990;263:2760-2765. [PubMed: 2271019]

Hall DB. Zero-inflated Poisson and binomial regression with random effects: a case study. Biometrics 2000;56:1030-1039. [PubMed: 11129458]

Harris KJ, Ahluwalia JS, Catley D, Okuyemi KS, Mayo MS, Resnicow K. Successful recruitment of minorities into clinical trials: The kick it at Swope project. Nicotine Tob Res 2003;5:575-584. [PubMed: 12959796]

Harris KJ, Golbeck AL, Cronk NJ, Catley D, Conway K, Williams KB. Timeline follow-back versus global self-reports of tobacco smoking: a comparison of findings with nondaily smokers. Psychol Addict Behav 2009a;23:368-372. [PubMed: 19586155]

Harris KJ, Stearns J, Kovach R, Harrar SW. Enforcing an outdoor smoking ban on a college campus: Effects of a multiple-component approach. Journal of American College Health 2009b;58:121-126. [PubMed: 19892648]

Hettema J, Steele J, Miller WR. Motivational Interviewing. Annual Review of Clinical Psychology 2005;1:91-111.

Jacob P 3rd, Wilson M, Benowitz NL. Improved gas chromatographic method for the determination of nicotine and cotinine in biologic fluids. J Chromatogr 1981;222:61-70. [PubMed: 6783675]

Johnston, L.; O’Malley, P.; Bachman, J.; Schulenberg, JE. College students and adults ages 19-45 (NIH Publication No. 07-6206). Bethesda, MD: National Institute on Drug Abuse; 2007. Monitoring the Future national survey results on drug use, 1975-2006: Volume II.

Kenford SL, Wetter DW, Welsch SK, Smith SS, Fiore MC, Baker TB. Progression of college-age cigarette samplers: what influences outcome. Addict Behav 2005;30:285-294. [PubMed: 15621399]

Lundahl BW, Kunz C, Brownell C, Tollefson D, Burke BL. A Meta-Analysis of Motivational Interviewing: Twenty-Five Years of Empirical Studies. Res Social Work Prac 2010;20:137-160.

McClure JB, Divine G, Alexander G, Tolsma D, Rolnick SJ, Stopponi M, Richards J, Johnson CC. A comparison of smokers' and nonsmokers' fruit and vegetable intake and relevant psychosocial factors. Behav Med 2009;35:14-22. [PubMed: 19297300] 
McPhillips JB, Eaton CB, Gans KM, Derby CA, Lasater TM, McKenney JL, Carleton RA. Dietary differences in smokers and nonsmokers from two southeastern New England communities. J Am Diet Assoc 1994;94:287-292. [PubMed: 8120293]

Miller WR. Motivational interviewing: Research practice and puzzles. Addictive Behaviors 1996;21:835-842. [PubMed: 8904947]

Miller, WR.; Rollnick, S. Motivational interviewing: Preparing people to change addictive behavior. New York: Guilford Press; 1991.

Miller WR, Rollnick S. Teaching motivational interviewing: Materials for trainers. 1999

Miller, WR.; Rollnick, S. Motivational Interviewing: Preparing people for change. 2nd ed.. New York: Guilford Press; 2002.

Moran S, Wechsler H, Rigotti NA. Social smoking among US college students. Pediatrics 2004;114:1028-1034. [PubMed: 15466101]

Murphy-Hoefer R, Griffith R, Pederson LL, Crossett L, Iyer SR, Hiller MD. A review of interventions to reduce tobacco use in colleges and universities. American Journal of Preventive Medicine 2005;28:188-200. [PubMed: 15710275]

Murray DM, Perry CL. The measurement of substance use among adolescents: when is the 'bogus pipeline' method needed? Addict Behav 1987;12:225-233. [PubMed: 3661275]

Okuyemi KS, James AS, Mayo MS, Nollen N, Catley D, Choi WS, Ahluwalia JS. Pathways to Health: A Cluster Randomized Trial of Nicotine Gum and Motivational Interviewing for Smoking Cessation in Low-Income Housing. Health Educ Behav 2007;34:43-54. [PubMed: 16778147]

Pbert L, Osganian SK, Gorak D, Druker S, Reed G, O'Neill KM, Sheetz A. A school nurse-delivered adolescent smoking cessation intervention: a randomized controlled trial. Prev Med 2006;43:312320. [PubMed: 16828858]

Prokhorov AV, Yost T, Mullin-Jones M, de Moor C, Ford KH, Marani S, Kilfoy BA, Hein JP, Hudmon KS, Emmons KM. "Look at your health": outcomes associated with a computer-assisted smoking cessation counseling intervention for community college students. Addict Behav 2008;33:757-771. [PubMed: 18280668]

Resnicow K, McCarty F, Baranowski T. Are precontemplators less likely to change their dietary behavior? A prospective analysis. Health Educ Res 2003;18:693-705. [PubMed: 14654502]

Richter KP, Gibson CA, Ahluwalia JS, Schmelzle KH. Tobacco use and quit attempts among methadone maintenance clients. Am J Public Health 2001;91:296-299. [PubMed: 11211643]

Rigotti NA, Lee JE, Wechsler H. US college students' use of tobacco products: results of a national survey. JAMA 2000;284:699-705. [PubMed: 10927777]

Rubak S, Sandbaek A, Lauritzen T, Christensen B. Motivational interviewing: a systematic review and meta-analysis. Br J Gen Pract 2005;55:305-312. [PubMed: 15826439]

The SAS System. 9.1.3 ed.. Cary, NC: SAS Institute;

Sobell, LC.; Sobell, MB. Timeline Folllow-Back: A technique for assessing self-reported alcohol consumption. In: Litten, R.; Allen, J., editors. Measuring Alcohol Consumption. Totowa, NJ: The Humana Press Inc.; 1992. p. 41-72.

Soria R, Legido A, Escolano C, Lopez Yeste A, Montoya J. A randomised controlled trial of motivational interviewing for smoking cessation. Br J Gen Pract 2006;56:768-774. [PubMed: 17007707]

Spierto FW, Hannon WH, Kendrick JS, Bernet JT, Pirkle JL, Gargiullo P. Urinary cotinine levels in women enrolled in a smoking cessation study during and after pregnancy. Journal of SmokingRelated Diseases 1988;2:65-76.

Subar AF, Harlan LC, Mattson ME. Food and nutrient intake differences between smokers and nonsmokers in the US. Am J Public Health 1990;80:1323-1329. [PubMed: 2240298]

Sutfin EL, Reboussin BA, McCoy TP, Wolfson M. Are college student smokers really a homogeneous group? a latent class analysis of college student smokers. Nicotine Tob Res 2009;11:444-454. [PubMed: 19264866]

Thompson B, Coronado G, Chen L, Thompson LA, Halperin A, Jaffe R, McAfee T, Zbikowski SM. Prevalence and characteristics of smokers at 30 Pacific Northwest colleges and universities. Nicotine Tob Res 2007;9:429-438. [PubMed: 17365775] 
Thompson B, McLerran D, Livaudais JC, Coronado GD. A group-randomized tobacco trial among 30 Pacific Northwest colleges: results from the Campus Health Action on Tobacco study. Nicotine Tob Res 2010;12:635-646. [PubMed: 20447935]

Travis HE, Lawrance KA. Randomized controlled trial examining the effectiveness of a tailored selfhelp smoking-cessation intervention for postsecondary smokers. J Am Coll Health 2009;57:437444. [PubMed: 19114383]

U.S. Census Bureau, 2009. College Enrollment of Students 14 Years Old and Over, by Type of College, Attendance Status, Age, and Gender: October 1970 to 2007. 2009.

US Department of Commerce, Census Bureau. National Cancer Institute and Centers for Disease Control and Prevention Co-sponsored Tobacco Use Supplement to the Current Population Survey (2001 2002). 2004.

Valanis B, Lichtenstein E, Mullooly JP, Labuhn K, Brody K, Severson HH, Stevens N. Maternal smoking cessation and relapse prevention during health care visits. Am J Prev Med 2001;20:1-8. [PubMed: 11137767]

Varvel SJ, Cronk NJ, Harris KJ, Scott AB. Adaptation of a Lay Health Advisor Model as a Recruitment and Retention Strategy in a Clinical Trial of College Student Smokers. Health Promot Pract. 2008

Wakefield M, Olver I, Whitford H, Rosenfeld E. Motivational interviewing as a smoking cessation intervention for patients with cancer: randomized controlled trial. Nurs Res 2004;53:396-405. [PubMed: 15586136]

Waters K, Harris KJ, Hall S, Nazir N, Waigandt A. Characteristics of Social Smoking Among College Students. Journal of American College Health 2006;55:133-139. [PubMed: 17175899]

Wellman RJ, DiFranza JR, Savageau JA, Dussault GF. Short term patterns of early smoking acquisition. Tob Control 2004;13:251-257. [PubMed: 15333880]

Wellman RJ, DiFranza JR, Savageau JA, Godiwala S, Friedman K, Hazelton J. Measuring adults' loss of autonomy over nicotine use: the Hooked on Nicotine Checklist. Nicotine Tob Res 2005;7:157161. [PubMed: 15804688]

Wetter DW, Kenford SL, Welsch SK, Smith SS, Fouladi RT, Fiore MC, Baker TB. Prevalence and predictors of transitions in smoking behavior among college students. Health Psychology 2004;23:168-177. [PubMed: 15008662] 


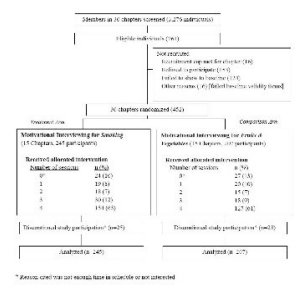

Figure 1.

Flow of chapters and participants, University in the Midwest, USA, 2006-2009 


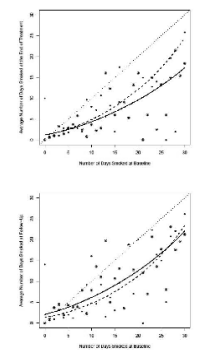

Figure 2.

Zero-inflated Poisson Mixed Model of the relationship between days smoked at baseline and end of treatment (top panel) and baseline and 6 month follow up (lower panel), University in the Midwest, USA 2006-2009 
Table 1

Characteristics of Study Participants at Baseline by Condition, University in the Midwest, USA, 2006-2009

\begin{tabular}{|c|c|c|c|}
\hline & $\begin{array}{l}\text { Smoking } \\
(\mathrm{n}=\mathbf{2 4 5})\end{array}$ & $\begin{array}{l}\text { Fruits/Vegetables } \\
(\mathbf{n = 2 0 7 )}\end{array}$ & p-value \\
\hline \multicolumn{4}{|l|}{ Chapter Factors } \\
\hline Sororities & 6 & 7 & \\
\hline Fraternities & 9 & 8 & \\
\hline \multicolumn{4}{|l|}{ Demographic Characteristics } \\
\hline Mean age (SD) & $19.4(1.1)$ & $19.4(1.01)$ & .74 \\
\hline Range & $18-22$ & $18-22$ & \\
\hline Female $(\%)$ & 35.5 & 57.5 & .00 \\
\hline Non-White $(\%)$ & 4.1 & 6.3 & .59 \\
\hline Year in school (\%) & & & .18 \\
\hline Freshman & 24.9 & 18.4 & \\
\hline Sophomore & 35.9 & 38.3 & \\
\hline Junior & 24.9 & 27.2 & \\
\hline Senior & 13.9 & 15.5 & \\
\hline Other & 0.4 & 0.5 & \\
\hline Alcohol use last 30 days (\%) & & & .11 \\
\hline$<5$ Days & 10.3 & 10.1 & \\
\hline 6-9 Days & 19.8 & 25.6 & \\
\hline 10-19 Days & 49.8 & 49.0 & \\
\hline >20 Days & 20.1 & 14.5 & \\
\hline Mean servings F\&V (SD) & $3.35(1.76)$ & $3.34(1.87)$ & .60 \\
\hline Median academic grade (IQR) & $\mathrm{B}+\left(\mathrm{A}^{-}, \mathrm{B}\right)$ & $\mathrm{B}+(\mathrm{A}-, \mathrm{B})$ & .70 \\
\hline Live in Fraternity/Sorority house (\%) & 64.5 & 64.3 & .89 \\
\hline \multicolumn{4}{|l|}{ Participate in Greek activities (in hours/week) } \\
\hline Mean (SD) & $7.8(7.2)$ & $7.7(6.2)$ & .97 \\
\hline Median (IQR) & $6(3,10)$ & $6(4,10)$ & \\
\hline \multicolumn{4}{|l|}{ Smoking-Related Characteristics } \\
\hline Number of days Smoked of past 30 days (\%) & & & .78 \\
\hline$<5$ days & 41.5 & 42.0 & \\
\hline 6-29 days & 47.3 & 43.7 & \\
\hline 30 days & 11.1 & 14.3 & \\
\hline \multicolumn{4}{|l|}{ Number of days smoked of past 30 days } \\
\hline Mean & $8.7(10.5)$ & $7.5(10.5)$ & .31 \\
\hline Median (IQR) & $3(0,14)$ & $2(0,12.8)$ & \\
\hline \multicolumn{4}{|l|}{ Cigarettes smoked on smoking days } \\
\hline Mean & $3.4(2.9)$ & $3.6(4.0)$ & .61 \\
\hline Range & $1-17$ & $1-23$ & \\
\hline Time to first cigarette, $\mathrm{n}(\%)$ & & & .18 \\
\hline 6-30 minutes & $9(3.9)$ & $11(5.8)$ & \\
\hline $31-60$ minutes & $9(3.9)$ & $10(5.2)$ & \\
\hline
\end{tabular}




\begin{tabular}{|llll|}
\hline & $\begin{array}{l}\text { Smoking } \\
(\mathbf{n = 2 4 5})\end{array}$ & $\begin{array}{l}\text { Fruits/Vegetables } \\
(\mathbf{n = 2 0 7})\end{array}$ & p-value \\
\hline \multicolumn{1}{|c}{ >60 minutes } & $212(92.2)$ & $170(89.0)$ & \\
Mean addiction (HONC) score (SD) & $2.4(2.4)$ & $2.4(2.6)$ & .81 \\
Mean motivation to quit (SD) & $5.4(2.8)$ & $5.6(3.1)$ & .51 \\
Mean confidence to quit (SD) & $8.9(1.8)$ & $9.0(1.9)$ & .58 \\
Considers self as smoker (\%) & 29.8 & 27.5 & .58 \\
Smoking friends & & & .09 \\
$\quad$ Best friends smoke (MD/IQR) & $2(1,3)$ & $2(1,3)$ & .45 \\
$\quad$ Girl/Boyfriend smokes (\%) & 14.9 & 17.8 & .31 \\
Used other forms of tobacco in the past 30 days (\%) & & & .50 \\
Cigars & 36 & 31 & .19 \\
$\quad$ Smokeless/Spit & 24.5 & 21.7 & \\
Beedies & 3 & 1 & \\
\hline
\end{tabular}

Notes: $\mathrm{SD}=$ Standard Deviation, IQR = Interquartile Range; $\mathrm{MD}=$ Median 


\section{Table 2}

30 Day quit rates for end of treatment (EOT) and follow-up (FU) for treatment groups: Intention to treat, University in the Midwest, USA, 2006-2009

\begin{tabular}{lllll}
\hline & $\begin{array}{l}\text { Smoking } \\
(\mathbf{n = 2 4 5})\end{array}$ & $\begin{array}{l}\text { F\&V } \\
(\mathbf{n = 2 0 7})\end{array}$ & OR $(\mathbf{9 5 \%}$ CI) & $\mathbf{p}$ \\
\cline { 2 - 5 } EOT & $77(31.4 \%)$ & $58(28.0 \%)$ & $1.20(.72,1.99)$ & .48 \\
FU & $50(20.4 \%)$ & $51(24.6 \%)$ & $0.78(.50,1.22)$ & .28 \\
\hline
\end{tabular}




\section{Table 3}

Any attempt to quit through end of treatment (EOT) and follow-up (FU) for treatment groups, University in the Midwest, USA, 2006-2009

\begin{tabular}{lllll}
\hline & $\begin{array}{l}\text { Smoking } \\
(\mathbf{n = 2 2 1})\end{array}$ & $\begin{array}{l}\text { F\&V } \\
(\mathbf{n = 1 8 0})\end{array}$ & OR $(\mathbf{9 5 \%}$ CI $)$ & $\mathbf{p}$ \\
\cline { 2 - 5 } EOT & $45.2 \%$ & $32.2 \%$ & $1.75(1.11,2.74)$ & .02 \\
FU & $62.9 \%$ & $50.6 \%$ & $1.66(1.11,2.47)$ & .01 \\
\hline
\end{tabular}




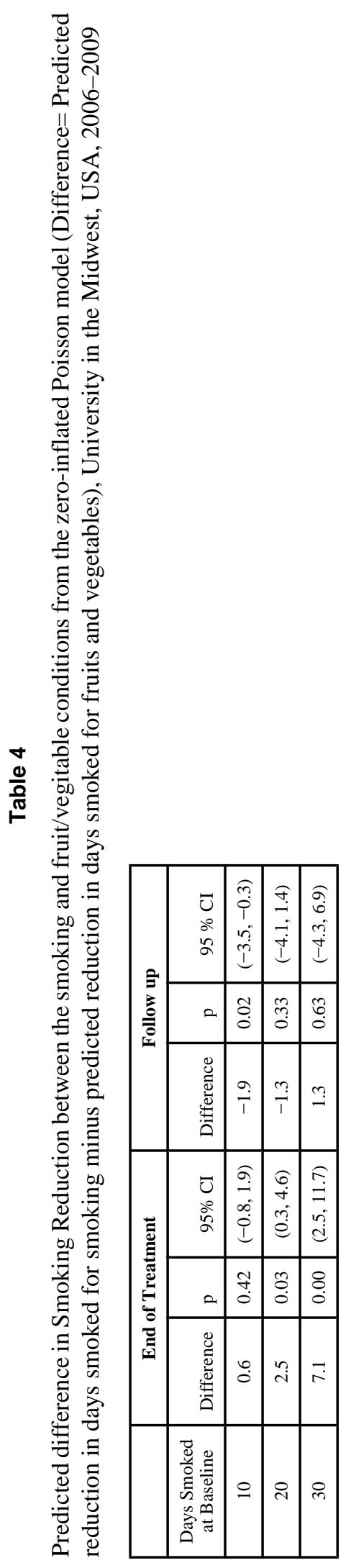

